\title{
Method of Freon Leak Detection and Dirty Air Filter in Air Conditioning for Electrical Savings
}

\author{
Ali A. S. Ramschie \\ Department of Computer \\ Engineering \\ Manado State Polytechnic
}

\author{
Johan F. Makal \\ Department of Electrical \\ Engineering \\ Manado State Polytechnic
}

\author{
Veny V. Ponggawa \\ Department of Computer \\ Engineering \\ Manado State Polytechnic
}

\begin{abstract}
The increase in electrical energy consumption of Air Conditioning can be caused by Freon leakage and dirty air filter. When the Freon leak occurs and air filter have been dirty, the compressor of the equipment will operate continuously until the temperature is maintained a desired setpoint, this may lead to an increase in electricity consumption of the equipment. The purpose of this research is how to build a control system that can detect and inform the user of Air Conditioning when the Freon gas has been leaked and the air filter has been dirty, so the user can know when the Air Conditioning needs to maintenance and the type of maintenance should be done, in order that can avoid the waste of electricity consumption. The system is built by integrating temperature sensor modules, current sensors, LCD displays and alarms into the Controller to control the overall workings of the system through the software embedded into it. System testing is done by simulating it through Proteus simulation program. From the results of tests conducted, it turns out that the resulting method can disable the working of Air Conditioning when indicated Freon has been leaked or the air filter has been dirty, and can inform to the user through the LCD display and alarm indicator, that the equipment needs to maintenacefor reduce the occurrence of electricity waste.
\end{abstract}

\section{Keywords}

Detection, Information, Freon Leakage, Dirty Air Filters, Air Conditioning.

\section{INTRODUCTION}

To achieve high quality of Air Conditioning work, good maintenance of each component is a key requirement for optimum cooling [1][2].

Wasting electrical energy in air conditioning can be caused by dirty air filter from air conditioning, it makes the air circulation through the air filter can't be detected when comparing the room temperature with the setting temperature, because it is hampered by the buildup of dust on the air filter. This condition makes the waste of electrical energy resulting from the compressor which continuously try to achieve room temperature as a desire set point. Wastage of electrical energy in air conditioning can also be caused due to leaked Freon, so the cooling room is not reached [3].

The integrated system in the manufacture of the Freon leakand the dirty air filter detection system on Air Conditioning supported by Arduino Uno microcontroller that serves as the overall system work regulator [4][5], ACS712 current sensor which serves as a detector of increased current consumption from the use of equipment Air Conditioning [6] [7], crystal liquid display (LCD) that serves to display information in connection with the state of Air Conditioning equipment, buzzer that functioned as an alarm to inform that the Air Conditioning needs to be maintenance, temperature sensors that functioned as a temperature change detector when Air Conditioning operates, in order to inform the controller of the type of treatment to be performed on Air Conditioning equipment and electronic components as a supporting component in the manufacture of the system.

To run the Freon gas leak and the dirty air filter detector system in Air Conditioning, a program that is embedded into Arduino Uno microcontroller, Arduino IDE as a software program, with reference to the algorithm of flowchart [8][9].

Researches related to this paper have been widely practiced as conducted by that

1. Chiou,et al (2008), published in the journal Energy and Buildings entitled "The study of energy-saving strategy for direct expansion air conditioning system", in which research is related to energy-saving procedures in DX Air Conditioning system, with periodic downtime method, by setting the system's operating period and the system shutdown period of two ACs [10].

2. Widell, et al. (2009) published in the International Journal of Refrigeration under the title "Reducing power consumption in multi-compressor refrigeration system", using linear programming model to minimize the compressor's electric energy consumption, the compressor's operation will be optimized according to the required load [11].

3. Zhou, et al (2007), published in the journal Energy and Buildings entitled "Energy simulation in the variable refrigerant flow air-conditioning system under cooling conditions", this research compare the energy consumption from air conditioning system with 3 different methods, namelyVariableRefrigerantFlow (VRF) system, VariableAirVolume (VAV) system and fan-coil plus fresh air (FPFA) system. The study was conducted with a simulation using the Energy Plus software. Simulation results show that the energy-saving potential of the VRF system reaches $22.2 \%$ and $11.7 \%$, compared to VAV and FPFA systems [12].

\section{METHODOLOGI}

The method used in this research is the design and manufacture method, which includes the design and manufacture of the system, in the form of integrated control circuit and software for running the whole system, and system testing process is done by simulating it through Proteus simulation program.

\subsection{Study Design Module}

System design was made to facilitate the process of system building by modeling it in Block Diagram, as shown in Figure 1. 
Caption :

- Arduino Uno R3 microcontroller serves as a regulator of the entire system.

- On / off Button, function to enable and disable system.

- Reset button, serves to reset the system when it is indicated that the Air Conditioning needs to be maintained (indicated by the active alarm indicator).

- Alarm indicator, serves as a medium of information when indicated Air Conditioning needs to maintenance, marked with Buzzer sound and LED blink.

- Driver relay, serves to enable and disable the working of Air Conditioning.

- Current sensor, serves as a detector of changes in electric current consumption of Air Conditioning.

- Temperature Sensor, serves as a detector of room temperature changes.

- LCD display, serves as a medium of information in connection with the state of Air Conditioning.

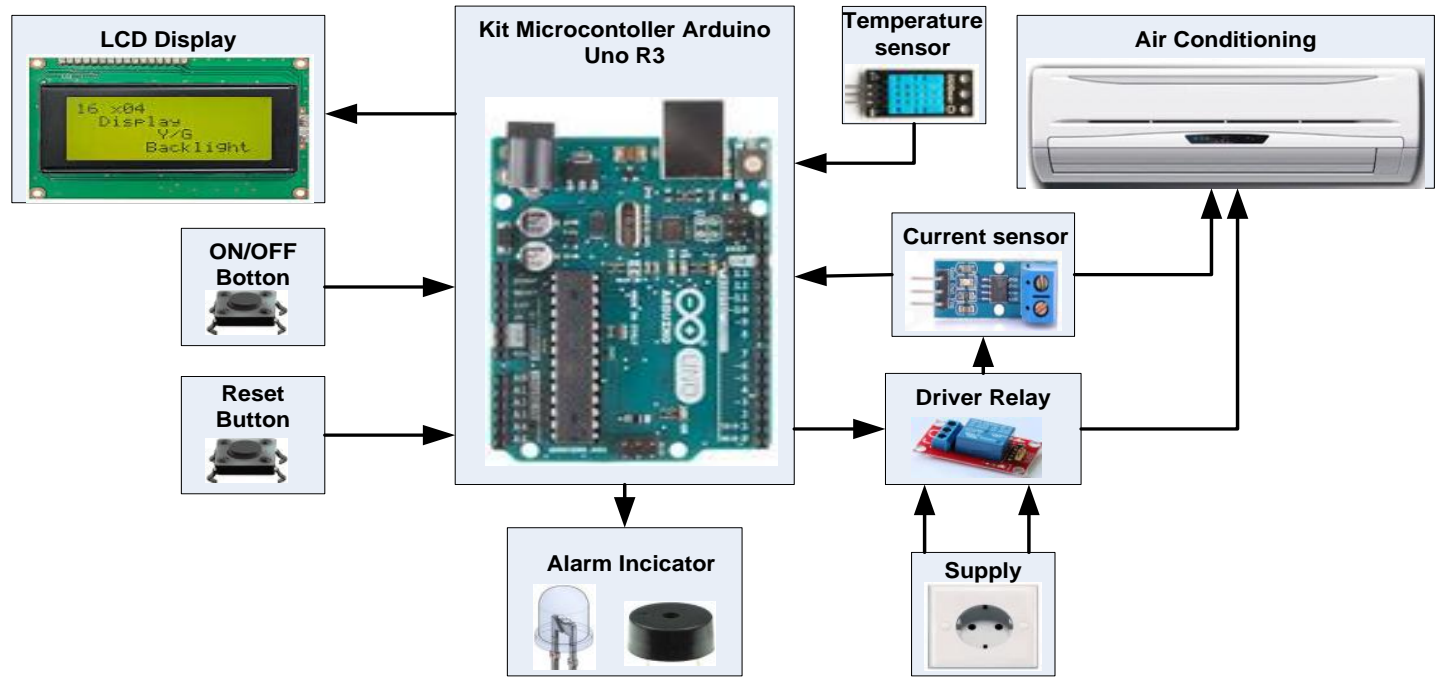

Fig. 1 Block diagram system

\subsection{Flowchart System (Algorithm)}

Flowchart system is represents an algorithm, workflow or process for a system. This system flowchart is shown in Figure 2.

Description algorithm of the system as follows:

- Initial stage, the system will read the state of the ON button. If pressed, then the system will be activated, if does not pressed, then the system remains in the early stages.

- Once the system is on, AC equipment will be activated through the relay driver circuit.

- Then the system will read the state of whether the off button is pressed or not, if pressed, the system will turn off the air conditioning equipment work, then the system back to stage 1. If the off button is not pressed, then the system goes to the next stage.

- The next step, read current sensor data through ADC then compare with setpoint value.

- If current sensor data is in the range of setpoint values when the compressor is on (outdoor and indoor), then the system will calculate the electrical energy consumption (Wh) and the amount paid (IDR) and displayed through the

- If current sensor data is in the range of setpoint values when the compressor is off (only indoor is active), the system will calculate the electrical energy consumption (Wh) and the amount paid (IDR) and displayed through the LCD display.

- If the current sensor data is greater than the setpoint value followed by the increased consumption of electric current for the compressor because air filter has been dirty, then the system will turn off the air conditioning and read the temperature sensor data.

- If the temperature sensor data is smaller or equal to the setpoint value, then the system will inform through the
LCD display that the air filter is dirty.

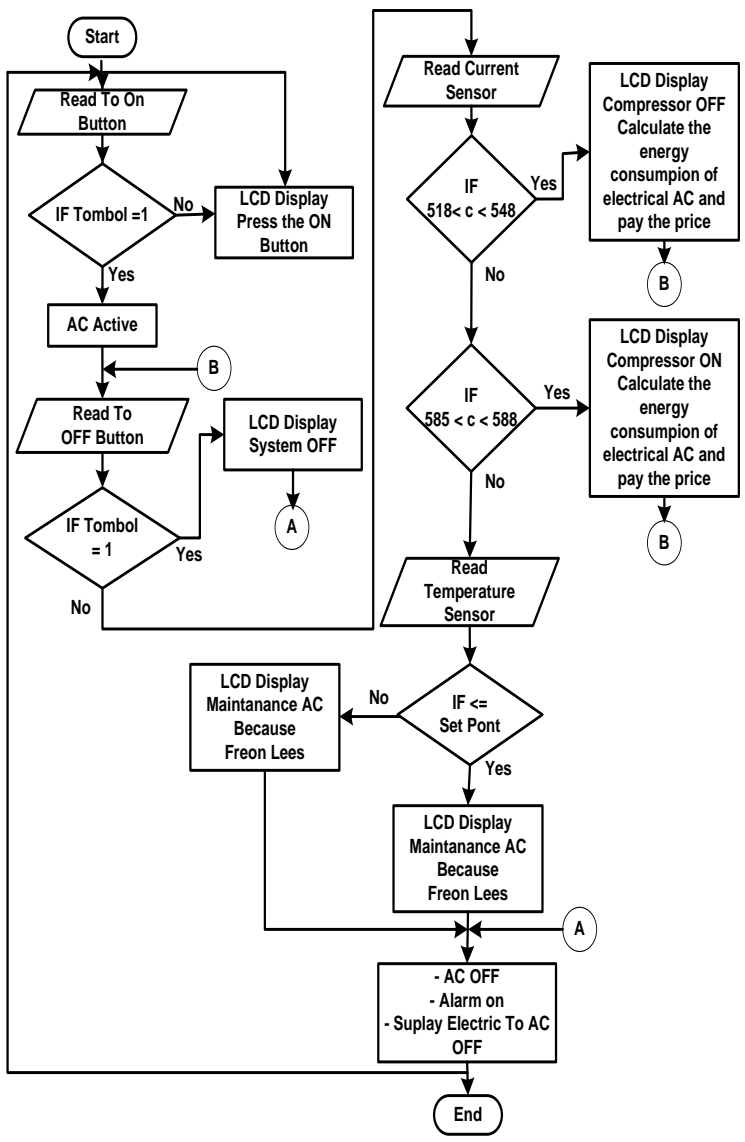

Fig.2 Flowchart system 
- If the temperature sensor data is greater than the set point value, then the system will inform through the LCD display that the Freon gas has been leaked.

- The next step is read the state of the reset button to disable the alarm and inform the system that it must be turned off to maintain the air conditioning.

- After the maintenance process is carried out, the operation of the system returns to an early stage.

\subsection{Sistem Design}

System design refers to the block diagram that has been created, in which circuit modules such as temperature sensor module, current sensor module, input button (On / Off and Reset Button), Alarm module, Relay module and LCD display module are integrated To the Arduino Uno microcontroller that serves as the working controller of the whole system. Figure 3 shows the design of the system created.

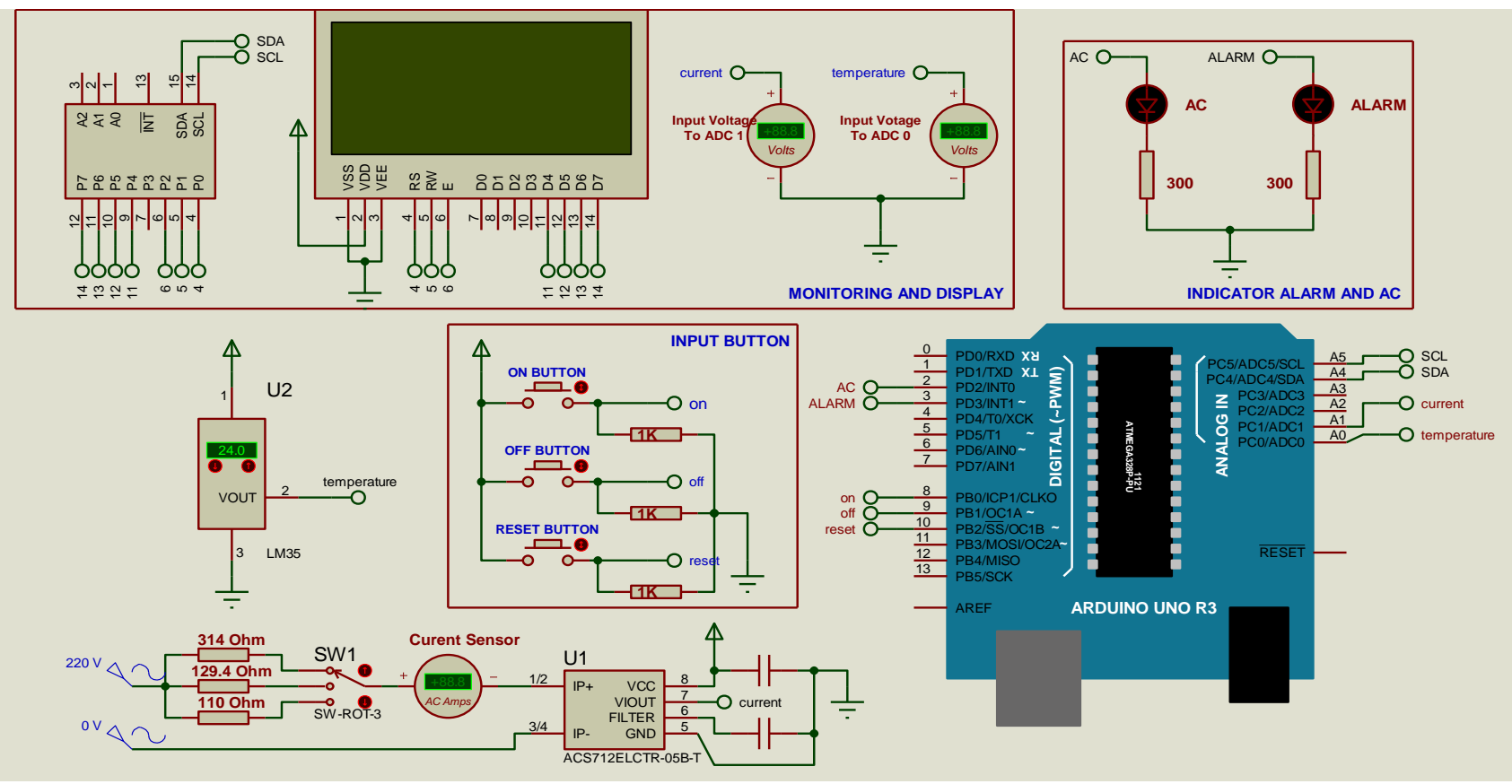

Fig. 3 System Design

\section{RESULT AND DISCUSSION}

The system testing process is done through the Proteus simulation program, by embedding a program created based on the program Algorithm through the Arduino IDE into the Arduino Uno controller. Stages of system testing as follows:

\subsection{System Testing When First Activation}

When the system is first activated, the LCD displays the system in OFF state, and to activate the system, please press the ON button. Figure 4 shows the display when the system is first activated.

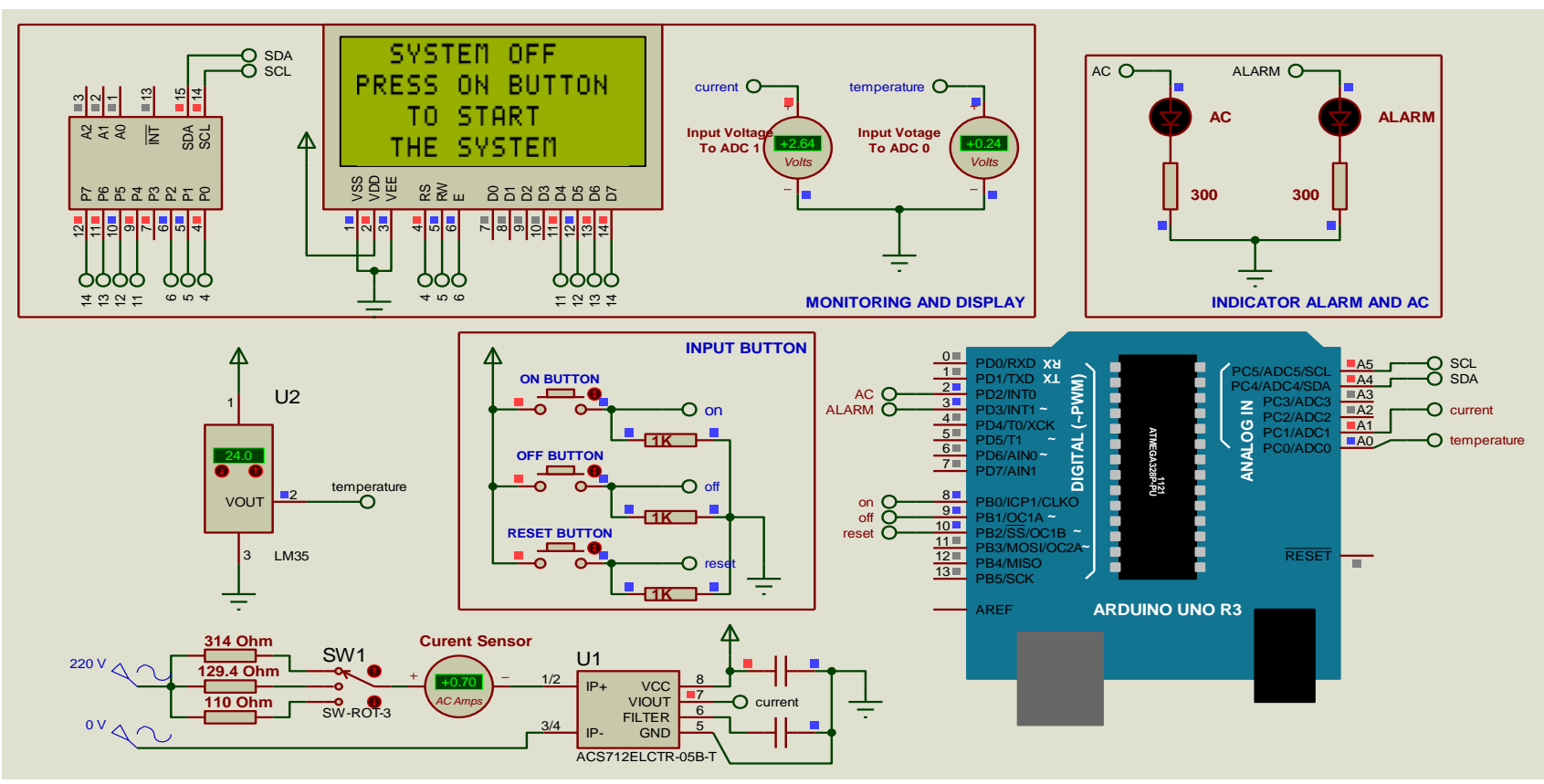

Fig. 4 Testing when the system was first activated 


\subsection{Testing When System Is ON}

When the ON button is pressed, air conditioning will be turned on and the current sensor will read the amount of current consumed by air conditioning, then the data will be process by the microcontroller and displayed it to the LCD display. Data displayed is the amount of electrical energy consumption and the price paid in rupiah. When the current sensor detects the current consumption of air conditioning is 0.7 amperes (use of air conditioning capacity of $0.5 \mathrm{PK}$ ), then the information is displayed to the LCD screen is the compressor OFF, which shows that only in indoor sections are active, while the outdoor inactive, Figure 5 shows the current state after the ON button is pressed.

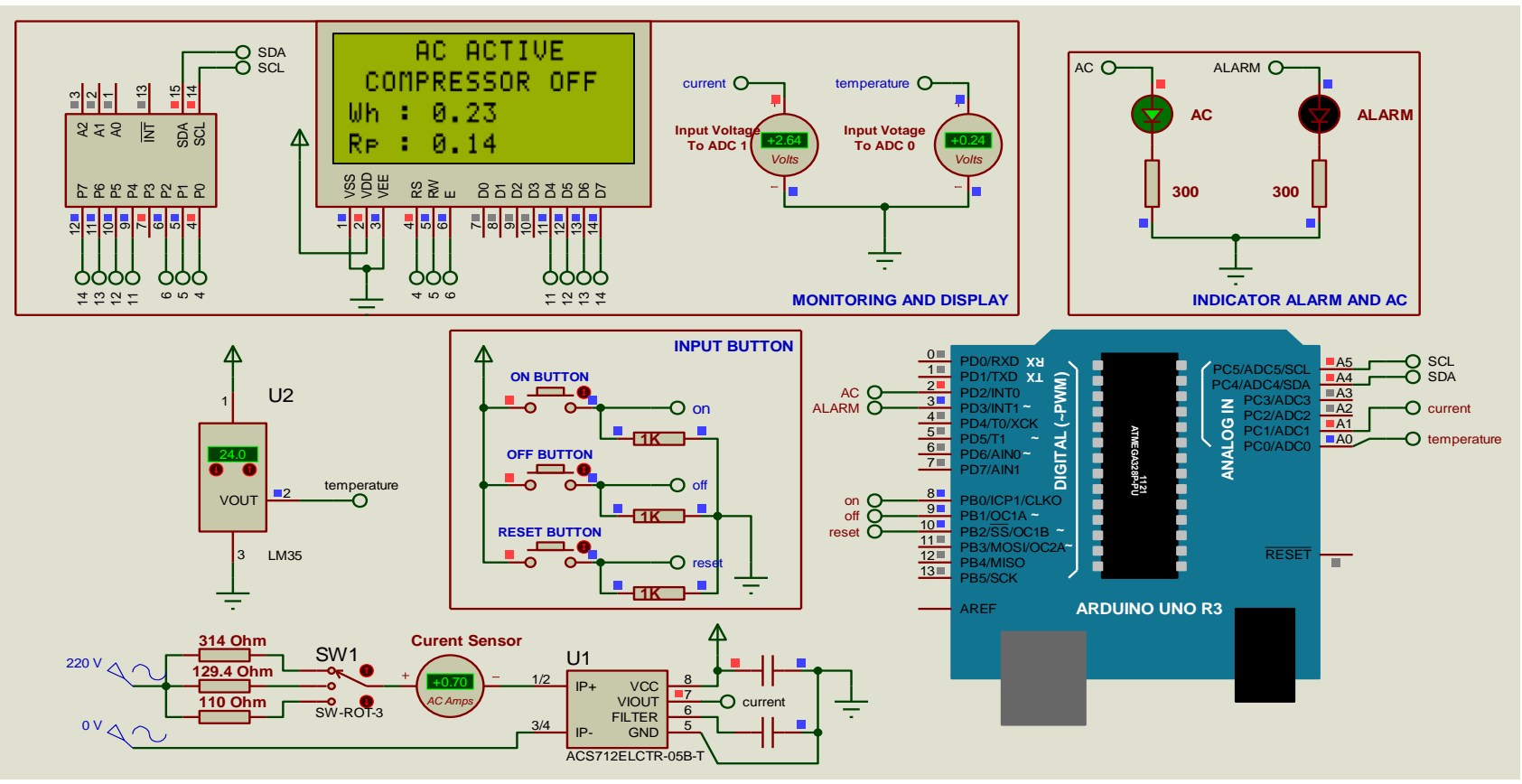

Fig. 5 Testing When the system is ON

When the current sensor detects current consumption of the air conditioning is 1.7 Ampere, the information to be displayed on the LCD screen is Compressor On and information about the amount of electricity consumption (Wh) and the paid price ( $\mathrm{Rp}$ ) of the air conditioning is detected through the current sensor. This information indicates that the active part is indoor and outdoor of the air conditioning. Figure 6 shows the test results when the compressor is on.

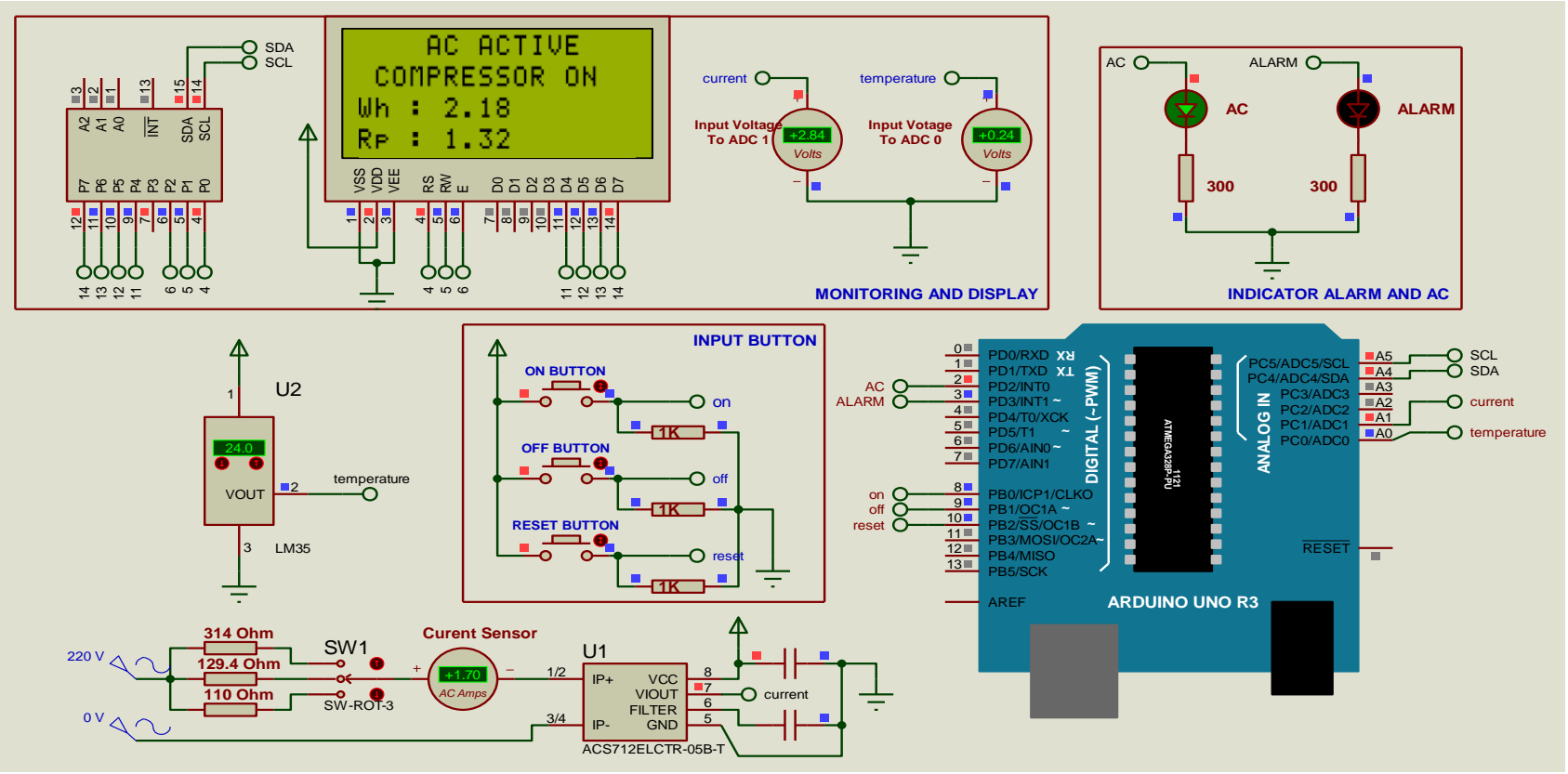

Fig. 6 Testing result when the compressor is on. 


\subsection{Testing When Indicated AC Needs To Be Maaintanance}

The test is done by adjusting the amount of AC current consumed to 2 amperes. When the current sensor detects an increase in the electric AC current consumption to 2 amperes, information from the current sensor will be processed by the controller which indicate that the $\mathrm{AC}$ equipment must be maintained. Then the controller will disable the AC function, and activate the alarm as an indication that the air conditioning needs to be maintained. The controller will detect the temperature changes of the room through the temperature sensor. If the detected room temperature is $28^{\circ} \mathrm{C}$ or more (no cooling process exists, since the Freon gas has been leaked), the controller will notify the user via the LCD screen that the maintenance that must be done on the $\mathrm{AC}$ is due to the leaked Freon gas, the test results shown in Figure 7. If the detected room temperature is smaller or equal to $24^{\circ} \mathrm{C}$ (the cooling process takes place in the room, but the compressor works continuously), the controller will notify the user via the LCD screen that the maintenance that must be done on the AC because the air filter which has been dirty, the test results shown in Figure 8.

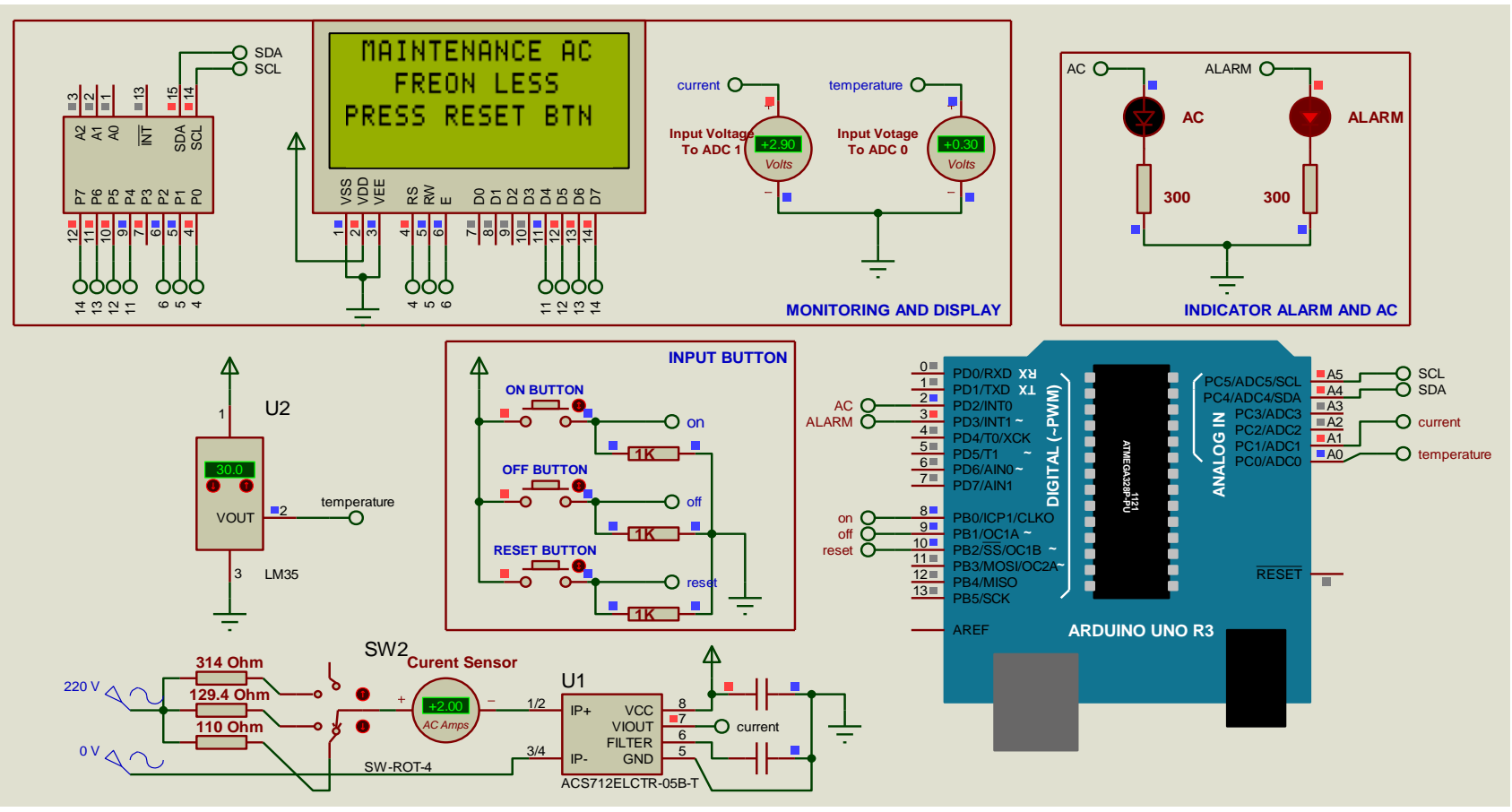

Fig. 7 Testing When the Freon has leaked.

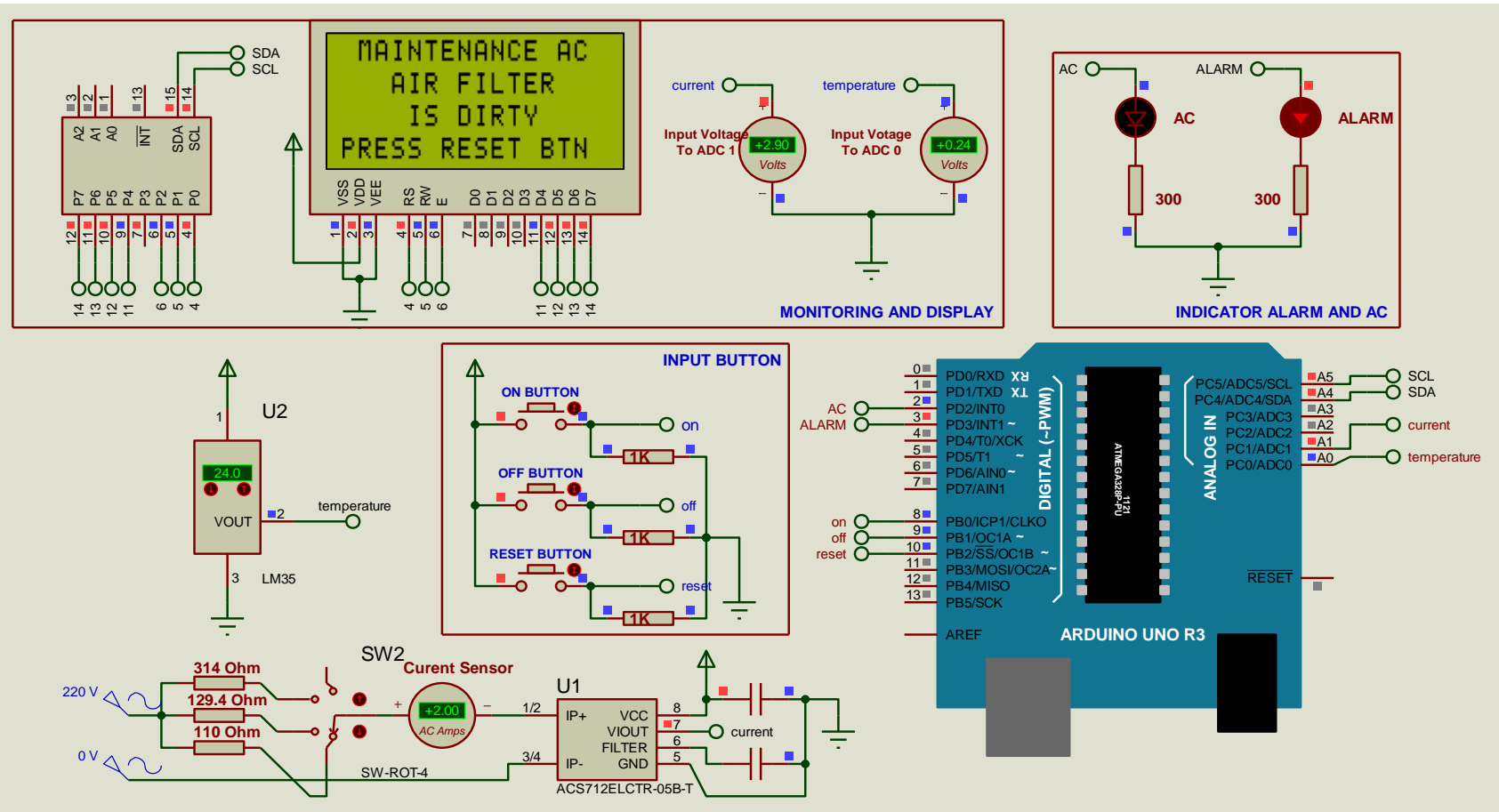

Fig. 8 Testing result when air filter is dirty 
To reset the system we must pressed the Reset button. When the Reset button is pressed, the system will turn off the alarm and the system will notify the user that the air conditioning should be maintained, then the system will return to the initial stage and activate the system. The test results are shown in Figure 9.

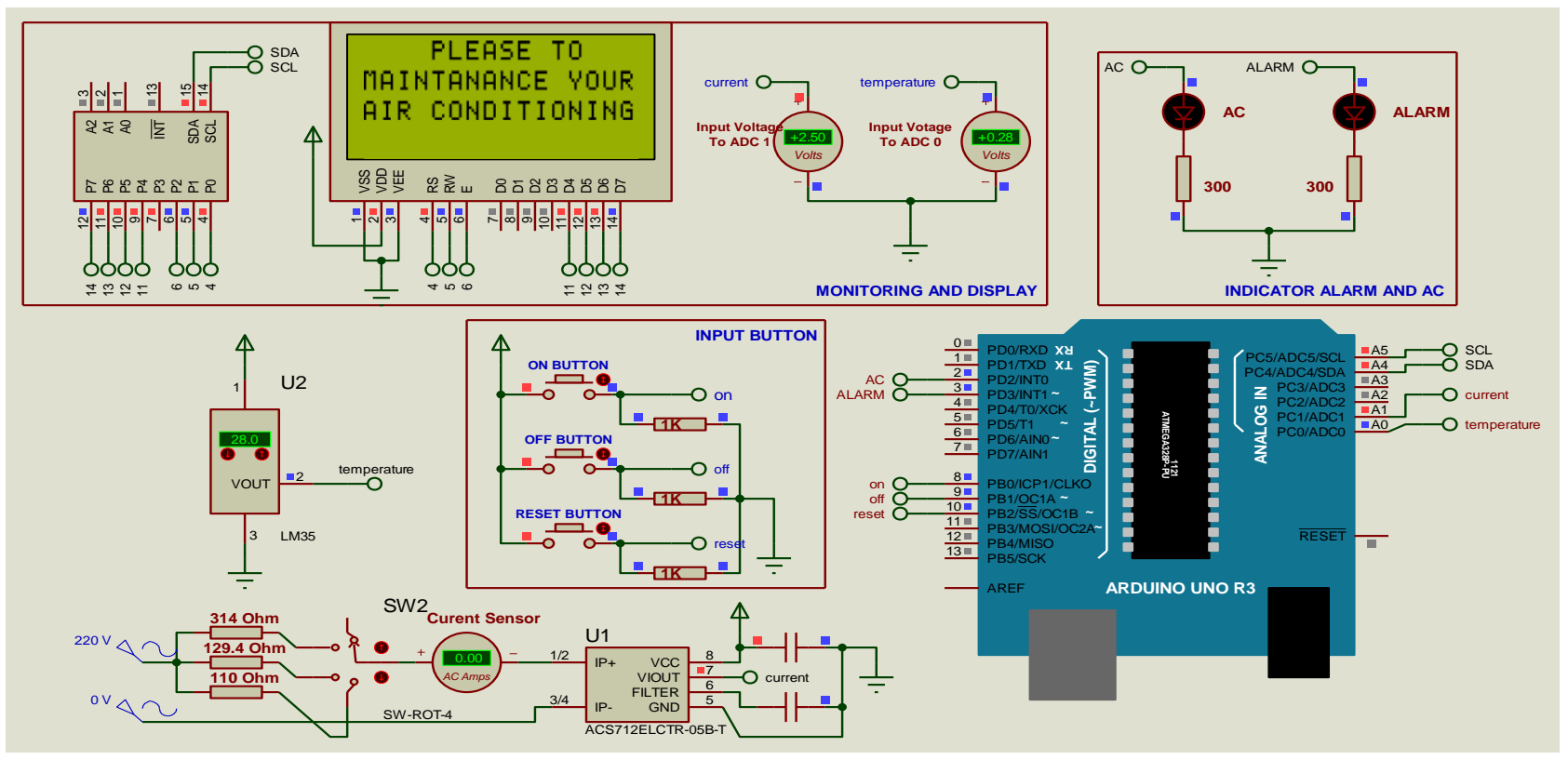

Fig. 9 Testing result when the reset button is pressed.

\section{CONCLUSIONS}

From the results of the tests conducted, it can be concluded that the resulting method of system detecting and informing lack of gas Freon and dirty air filter from air conditioning equipment for electricity savings this can disable the work of air conditioning equipment when indicated maintenance needs, Reduce the occurrence of waste of electrical energy. In addition, the resulting method can inform the user of air conditioning equipment through the alarm indicator and LCD display, that the necessary maintenance is caused by the Freon gas has been reduced or because of the air filter has been dirty, so that users can know the type of treatment to be performed Such air conditioning equipment. For the future, a program that has been created that refers to the design of the algorithm, can be implemented through an integrated control system and installed on air conditioning equipment, resulting in waste of electric energy caused by dirty air filters And because of the reduced gas freon From AC can be avoided.

\section{ACKNOWLEDGMENTS}

Thanks to the Ministry of Research and Technology of Technology and Higher Education, which has funded this research with competitive grants program in 2016, so as to do research and work well.

\section{REFERENCES}

[1] Buntarto, "Service dan Reparasi AC", Graha Ilmu, Yogyakarta, 2009

[2] Handoko J, "Merawat dan Memperbaiki AC", Kawan Pustaka, Jakarta, 2009.

[3] Hidayat T, "Analisis Penghematan Listrik pada AC Split dengan Refrigran Hidrokarbon disertai perbaikan faktor daya" Jurnal Teknosain Vol. 8, 2011.Alan G. Smith, "Introduction To Arduino," Alan G. Smith, 2011.
[4] Mitar Simic, "Design and Development of Air Temperature and Relative Humidity Monitoring System with AVR Processor base Web Server", Electrical and Power Engineering (EPE), International Conference and Expocition on, 2014.

[5] Husnawati, Rossi Passarella, Sutarno dan Rendyansyah, "Perancangan dan Simulasi Energi Meter Digital Satu Phasa Menggunakan Sensor Arus ACS712", JNTETI Vol. 2. No. 4, November 2013.

[6] Ilham, Amil Ahmad, and Ali Ramschie. "SISTEM MONITORING DAN KENDALI KERJA AIR CONDITIONING BERBASIS MIKROKONTROLLER ATmega 8535.", Jurnal Ristek Vol.2, No.1, Juni 2013.

[7] Ali A.S. Ramschie, Johan Makal, Veny Ponggawa, "Algorithms Air Conditioning Air Filter Detection System For Electric Energy Savings", International Journal of Computer Application (IJCA), Vol. 156 No. 8, 2016.

[8] M. Mossolly, K. Ghali, N. Ghaddar, "Optimal Control Strategy For a Multy-Zone Air Conditioning System Using The Genetic Algorithm", ELSEVIER Vol. 34, Issue 1, page 58-66, 2009.

[9] Chiou. C.B., Chu C.M. dan Lin, S.L. "The study of energisaving strategy for direct expansion air conditioning system"Energi and Buildings 40. 16601665,2008 .

[10] Widell. K.N. dan Eikevik. T. "Reducing power consumption in multi -compressor refrigeration sistems" International Journal of Refrigeration 33. 88-94,2009.

[11] Zhou, Y.P., Wu, J.Y., Wang, R.Z. \& Shiochi, S.“Energi simulation in the variable refrigerant flow airconditioning sistem under cooling conditions" Energi and Buildings 39. 212-220, 2007. 